\title{
The Relationship Between Learning Effectiveness and Cultural Identity of Overseas Students in China-the Regulating Role of Active Personality
}

\author{
Yao Jiang \\ International Business School \\ Yunnan University of Finance and Economics \\ Kunming, China \\ 2927789297@qq.com
}

\author{
Ying Yang* \\ International Business School \\ Yunnan University of Finance and Economics \\ Kunming, China \\ 11476423@qq.com
}

\begin{abstract}
This paper mainly takes the overseas students in Yunnan universities as the main subjects of the questionnaire. This paper studies the relationship between cultural identity and learning effectiveness of foreign students in China. Data were collected by questionnaire survey and analyzed by SPSS statistical software. The results show that, firstly, cultural identity has a positive impact on learning outcomes. The higher the degree of cultural identity is, the better the learning effect can be. Secondly, initiative personality has a positive impact on the learning effectiveness of foreign students. That is to say, the more active personality is, the better the learning effect is. Finally, in the relationship between foreign student's learning effectiveness and cultural identity, initiative personality has a positive effect, but the moderating effect is not significant. That is to say, in the relationship between cultural identity and learning effectiveness, whether a person is an active personality has no great influence on the mechanism. This paper enriches the research in the field of education for foreign students in China and provides a reference for improving the learning effectiveness of foreign students in China.
\end{abstract}

Keywords: learning effectiveness, overseas students in China, cultural identity, active personality

\section{INTRODUCTION}

With the proposal of the "one belt and one way" initiative, the overall strategy of opening up to the outside world in China in the new era is becoming clearer and clearer.

To promote the comprehensive development and in-depth cooperation between China and other countries along the way, we will also bring new opportunities and challenges to the internationalization of higher education in China. In particular, the education and management of international students in China should actively integrate into the "one belt and one way" strategy, so as to provide effective personnel protection and intellectual support for its comprehensive advancement. However, with the continuous expansion of the number of international students in China and the increasing pressure on education and management of overseas students, there is a great difference between the educational management concept of foreign students in universities and the cultures along the "one belt and one road". The methods of education

*Corresponding author management are still lagging behind, and there are many inadequacies.

By virtue of its unique geographic and relational advantages, Yunnan has carried out all-round and multi-level educational cooperation and exchanges for foreign students in South and Southeast Asia, and is actively building educational destinations for foreign students in South and Southeast Asian countries. This paper takes the overseas students from Yunnan University of Finance and Economics in China as the research sample, introduces the adjusting variable of initiative personality, and explores the relationship between cultural identity and learning effectiveness of overseas students in China. It is hoped that this will enrich the research in the field of foreign students' education in China and provide a reference for improving the learning effectiveness of foreign students in China. To help them adapt to the study and life of China, to enhance their cultural identity with China, to provide scientific basis for the formulation of educational measures in Colleges and universities, and to speed up the pace of internationalization of education in China. The structure of the paper is as follows: the second part constructs the relationship between initiative personality, learning effectiveness and cultural identity, and puts forward research hypotheses; the third part introduces data sources and research methods; the fourth part shows the results of analysis; the last parts are conclusions and discussions.

\section{LITERATURE REVIEW}

In the 1990s, Bateman \& Grant [1] put forward the concept of active personality. The so-called initiative personality refers to the individual's behavioral tendency to change the external environment by constantly exploring new ways, seizing opportunities and taking active actions, which is the stable individual characteristic of affecting the initiative behavior. Bateman and Grant believe that individuals with high initiative personality can identify opportunities, take action and persevere until they achieve their goals; on the contrary, people without initiative are passive and passive, and they are used to adapting to the environment and forced to change. There have been many studies on the variables of initiative personality and organizational outcomes, especially in the aspects of personal 
and organizational outcomes, such as personal job performance, job and life satisfaction, leadership [2], job promotion, organizational change and entrepreneurship [3], turnover intention and turnover rate. The lattice has significant predictive effect. For College students, the study of initiative personality is mostly in employment planning, career orientation, leadership, self-efficacy and other aspects, less used in other aspects of research. The known conclusions in these fields show that college students' initiative personality is on the upper middle level; college students' initiative personality has a predictive effect on career decision-making self-efficacy, and has a positive relationship. The higher the score of College Students' initiative personality, the higher the sense of career decision-making self-efficacy [4].However, there are few studies on whether initiative personality affects the learning effectiveness of foreign students.

Learning effectiveness refers to the overall test of students' learning outcomes by using various tests and evaluation tools after learning a paragraph, so as to understand how students learn about the learning content, and then to be regarded as a remedy for learning deficiencies or a reference for further learning [5]. Qifeng $\mathrm{Li}$ [6] in the "Student Classroom Experience and Learning Effectiveness Research", divides learning effectiveness into two dimensions: academic achievement and student satisfaction, in which students' objective academic achievement is used as a reference to measure the long-term effect of students' classroom learning; students' satisfaction is mainly based on students' classroom performance and other factors to measure the short-term effect of students' classroom learning. Students' learning effectiveness is defined as the learning results obtained by students in a certain learning input. In Ziwen Lu's "An Analysis of the Progress of Research on Learning Effectiveness at Home and Abroad", students' learning outcomes refer to the description of students' specific learning expectations, as well as the results of students' specific learning development and performance. Through the students' learning results, we can clearly describe what we expect students to know and understand and what can be done by applying what they know after completing the class hours or courses.

Cultural identity is human's inclined consensus and recognition of culture. Most Western scholars believe that cultural identity is the recognition or confirmation of selfimage. They believe that: "In social life, cultural identity is always related to specific cultural patterns, showing the degree of recognition of common culture among cultural members, and is the symbol of individuals and groups defining themselves and strengthening their sense of identity in order to condense into groups with common cultural connotations" [8].The study of cultural identity in China began with the concept of "pluralism as one" put forward by Mr. Xiaotong Fei [9].From the perspective of second language acquisition, cultural identity is an attitude of acceptance and recognition of different cultural characteristics, which includes three parts: cognition, emotion and behavior [10]

\section{PROPOSED HYPOTHESES}

\section{A. Cultural Identity and Learning Effectiveness}

Identity refers to the confirmation of something common or identical. Cultural identity refers to the recognition of common culture among people or between individuals and groups. Using the same cultural symbols, following the common cultural ideas, adhering to the common mode of thinking and behavior norms are the basis of cultural identity. Cultural identity includes identification with politics, economy and religion. It is people's consensus, recognition and acceptance of a certain culture in concept, psychology and behavior. Individuals living in different cultural systems have different cultural identities. For homogeneous cultural countries, because they have similar cultural traditions and habits, people are more likely to accept and recognize similar cultures.

The core idea of cultural identity is people's recognition of the cultural values. That is to say, the education of cultural identity for foreign students in China is essentially the education of their values. The core of value identity lies in the recognition and sharing of a certain value or a certain kind of value, which is manifested in the formation of common values. The formation and development of cultural identity requires conditions. The most important aspect is the social living environment in which individuals live. Individuals form a relatively mature state of cultural identity through continuous running-in and collision with their environment, and ultimately achieve the goal of cultural adaptation through this mature state of cultural identity.

Learning effectiveness refers to the improvement of students' knowledge ability and high learning effectiveness through a good learning situation and satisfactory interaction between teachers and students. The ratio of the comprehensive learning result of learners' learning behavior to the comprehensive learning cost of realizing the learning result is the comprehensive learning result of unit learning cost. At present, the awareness of Chinese culture among foreign students in China is still low, and the overall awareness is very insufficient.

A large number of foreign students in China generally feel that the negative transfer of their mother tongue culture leads to difficulties in understanding Chinese culture. Due to the different management systems of student status and accommodation between Chinese students and foreign students, most of the courses offered by foreign students in China are set up separately and live in apartments for foreign students. It is difficult to make Chinese friends, understand the actual living conditions of Chinese people, and understand many aspects of Chinese culture. Because they do not understand Chinese culture, lack of motivation for learning, low attendance rate, low learning efficiency, slow progress and high failure rate [11]. Based on this, the hypothesis is put forward:

Hypothesis 1: Cultural identity has a positive impact on learning effectiveness. The higher the degree of cultural identity is, the better the learning effect can be. 


\section{B. Initiative Personality and Learning Effectiveness}

Active personality refers to a stable tendency of individuals to take active action to influence their surroundings [12].This concept was first proposed by Bateman and Grant [1] in the study of organizational behavior. It is a new direction in the field of human resources research recently. Many studies have shown that there are individual differences in active personality, which further leads to significant differences in the behavior of these individuals in the environment [13] [14].People with strong initiative personality tendencies are not bound by external forces of the environment, but actively take action to promote change. They can aim at the opportunity ahead of time and act actively until the expectation is realized; while those with weak initiative are more passive and seldom act actively. They are always passively adapted or changed under the driving of external forces, and sometimes even passively endure the environment [12].

Grant [2] explored 131 real estate brokers for nine months. After controlling variables such as experience, intelligence, responsibility, extroversion and social approval, he found that initiative personality can explain $8 \%$ variation of personal work performance, and initiative personality has significant predictive power on work performance. Thompson [16] proposed from the perspective of social capital that active individuals achieve high performance by developing social networks. In China, a survey of 128 employees in three enterprises by Li Qing [17] shows that initiative personality is positively correlated with job performance. Participants with high scores on the Active Personality Scale had significantly higher job performance than those with low scores. Wen Yao and Yiqun Gan [18] took 253 employees from several Chinese local enterprises as subjects. The results also showed that after controlling Big Five personality and social approval, initiative personality predicted job performance and could explain $8.5 \%$ variation of job performance. The research of Xiaobing Zhao [19] also shows that initiative personality not only has a significant direct positive predictive effect on job performance (more than 15\%), but also can adjust the relationship between initiative personality and job performance by distributive equity. Jianchun Hao's research shows that there is a negative correlation between family life pressure, learning pressure, interpersonal relationship pressure and students' learning performance. There is a positive correlation between negative emotional adjustment and learning performance. In terms of learning satisfaction, there is a positive correlation between learning environment, teachers' quality and teaching attitude, teaching process satisfaction, interpersonal relationship satisfaction and learning performance, but there is no correlation between teaching public facilities satisfaction and learning performance. Thus, the following assumptions are put forward:

Hypothesis 2: Active personality has a positive impact on the learning effectiveness of foreign students. That is, the more active personality is, and the better the learning effect is.

Gong [20] show that highly motivated people is good at controlling their environment and actively acquiring resources to achieve their goals. Wen Fang and Jinping Mao [21] believe that initiative personality refers to a stable tendency of individuals to take initiative to influence their surroundings. Yang Bin [22] research results show that active personality is only a stable tendency of active behavior, is a unique personality trait different from the Big Five personality theory, and has not yet formed an independent personality theory. Therefore, personality represents a persistent attribute that is different from other people's thoughts and behaviors. This characteristic is not only an organizational structure with specific components, but also a dynamic characteristic that produces different reactions and results with different environments [23].

Active personality can regulate the relationship between job exclusion and organizational citizenship behavior. When employees have high initiative personality, job exclusion decreases, while organizational citizenship behavior increases. The more proactive personality is, the more prone the actor is to adopt positive coping strategies. When organizational members adopt positive coping strategies, there is a negative relationship between job exclusion and organizational citizenship behavior. [24] Social interpersonal interaction is an important concept in Cascarilla's theory. He believes that the socialized interaction of college students is closely related to all aspects of students' development, and its impact on students is far more useful than the structure and organizational characteristics of colleges and universities. Tinto used the theory of interaction to explain the dropout behavior of College students, pointing out that the essence of college life is "interactive integration", and social integration is generally measured by the interaction between students, teachers and interpersonal. The more successful the integration is, the greater the students' learning outcomes will be [25]. Individuals with initiative personality tend to identify new ways of solving problems through continuous learning, and constantly update their knowledge and skills, so as to put forward more new ideas and programs. Based on this, the following assumptions are put forward:

Hypothesis 3: Initiative personality has a positive moderating effect on the relationship between learning effectiveness and cultural identity of foreign students. That is to say, the higher the initiative personality, the better the learning effect of foreign students under certain circumstances of cultural identity.

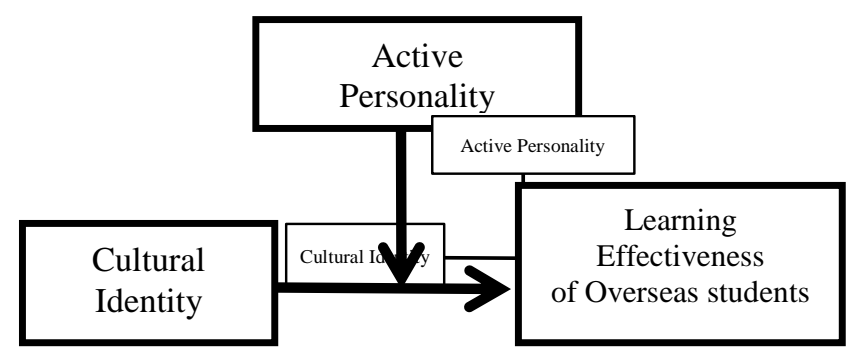

Fig. 1. The theoretical framework of the study

\section{RESEARCH METHODS}

\section{A. Sample Selection and Data Collection}

In this paper, Yunnan University students are the main object of study. E-mail and other means were used to send out 
electronic questionnaires to collect the questionnaires. A total of 150 questionnaires were sent out. All the questionnaires were collected and invalid questionnaires were put forward. 112 valid questionnaires were finally obtained. The rate of return was $75 \%$.Among the respondents, $45.16 \%$ were males and $54.84 \%$ were females. The average age was 27.Majors include project management, mechanical engineering, Chinese, etc. Their education backgrounds are Bachelor's degree, postgraduate and doctor's degree. Students come from Laos, Myanmar, the United States, Mauritius, Cambodia, Ethiopia and other countries.

TABLE I. TABLE OF VALID SAMPLE COMPOSITION

\begin{tabular}{|l|l|c|}
\hline \multicolumn{1}{|c|}{ Name } & \multicolumn{1}{|c|}{ Category } & Percentage \\
\hline \multirow{2}{*}{ Gender } & Male & $54.84 \%$ \\
& Female & $45.16 \%$ \\
\hline \multirow{3}{*}{ Age } & $20-24.5$ & $13.51 \%$ \\
& $25-29.5$ & $60.36 \%$ \\
\hline \multirow{3}{*}{ Education background } & $30-35$ & $26.13 \%$ \\
\hline \multirow{5}{*}{ Major } & Bachelor's degree & $7.53 \%$ \\
& postgraduate & $88.17 \%$ \\
& Doctor's degree & $4.30 \%$ \\
\hline \multirow{5}{*}{ Nationality } & project management & $20.54 \%$ \\
& mechanical engineering & $14.29 \%$ \\
& Chinese & $31.25 \%$ \\
& Else & $33.93 \%$ \\
\hline & Laos & $22.58 \%$ \\
& Cambodia & $19.35 \%$ \\
& Ethiopia & $17.20 \%$ \\
& Vietnam & $13.98 \%$ \\
& Myanmar & $13.98 \%$ \\
& United States & $8.60 \%$ \\
& Else & $4.30 \%$ \\
\hline
\end{tabular}

\section{B. Measuring Tools}

This research tool refers to the research scales or questionnaires of scholars at home and abroad. According to the main theories and research, three scales are obtained: learning effectiveness, cultural identity and initiative personality. The questionnaire consists of four items: the first is basic personal data; the second is cultural identity; the third is active personality; and the fourth is learning effectiveness.

The cultural identity scale of Zhao Jie [26] was adopted. There are 33 items in the scale. Likert's five-point scoring method is used to express "very disagreement", "comparative disagreement", "uncertainty", "comparative agreement" and "very agreement" with 1-5 respectively. The reliability of the scale is 0.83 .

For active personality, this study adopts Kemmerer-Mueller \& Wanberberg Active Personality Scale (APS) revised by Bateman \& Grant [27], which contains 10 questions, and is the most adopted research scale. The reliability coefficient of the scale is 0.89 , which is used to express "very disagreement", "comparative disagreement", "uncertainty", "comparative agreement" and "very agreement" respectively.

The Learning Effectiveness Scale was used by Jianchun Hao [7]. It is divided into two variables, a total of 9 questions. The questionnaire was scored by Richter's five-point scoring method, with 1-5 for "very disagreement", "comparative disagreement", "uncertainty", "comparative agreement" and "very agreement". The higher the average score, the higher the learning effectiveness. Among them, the reliability of ability factor dimension is 0.85 , and that of social factor dimension is 0.88 .

Because the questionnaires are sent to foreign students in Yunnan universities and the main language of communication is English, all the above forms are translated into English language for distribution. According to the relevant research, this study selected gender, age, education level, length of study as control variables.

\section{DATA ANALYSIS AND RESULTS}

In order to test whether there are common methodological deviations in this study, Harman single factor test was used to test the related statistical tests. The specific method is to put all the items of the questionnaire used in this study into exploratory factor analysis, and test the factor analysis without rotation. The result shows that the load of the first principal component is $33.95 \%$, which does not meet the $40 \%$ setting standard.

TABLE II. DESCRIPTIVE STATISTICAL ANALYSIS $(\mathrm{N}=112)$

\begin{tabular}{|l|c|l|l|l|l|l|l|l|}
\hline $\begin{array}{l}\text { Research } \\
\text { variables }\end{array}$ & $\mathbf{M}$ & SD & $\mathbf{1}$ & $\mathbf{2}$ & $\mathbf{3}$ & $\mathbf{4}$ & $\mathbf{5}$ & $\mathbf{6}$ \\
\hline 1. Gender & 1.45 & 0.50 & 1 & & & & & \\
\hline 2.Age & 27.73 & 3.61 & $0.566^{* *}$ & 1 & & & & \\
\hline $\begin{array}{l}\text { 3.Learning } \\
\text { stage }\end{array}$ & 1.96 & 0.31 & $0.250^{* *}$ & $0.806^{* *}$ & 1 & & & \\
\hline $\begin{array}{l}\text { 4.Cultural } \\
\text { Identity }\end{array}$ & 3.97 & 0.52 & 0.03 & 0.023 & 0.065 & 1 & & \\
\hline $\begin{array}{l}\text { 5.Active } \\
\text { personality }\end{array}$ & 4.00 & 0.58 & 0.08 & 0.014 & 0.129 & $0.653^{* *}$ & 1 & \\
\hline $\begin{array}{l}\text { 6.Learning } \\
\text { effectiveness }\end{array}$ & 4.10 & 0.55 & 0.25 & -0.142 & 0.033 & $0.695^{* *}$ & $0.711^{* *}$ & 1 \\
\hline
\end{tabular}

The above table shows that the correlation coefficient between cultural identity and learning effectiveness is 0.695 . It shows that cultural identity is positively correlated with learning effectiveness. With the improvement of cultural identity, learning effectiveness will increase. The above table also shows that the correlation coefficient between initiative personality and learning effectiveness is 0.711 , and the test results are significantly correlated. It shows that there is a positive relationship between initiative personality and learning effectiveness. The more obvious the initiative personality is, the better the learning effect is. The above information provides a good basis for the proof of hypothesis 1 and hypothesis 2 .

TABLE III. REGRESSION MODEL ANALYSIS OF CULTURAL IDENTITY AND LEARNING EFFECTIVENESS(N=112)

\begin{tabular}{|l|c|c|}
\hline \multirow{2}{*}{$\begin{array}{c}\text { Models and } \\
\text { variables }\end{array}$} & \multicolumn{2}{|c|}{ Learning effectiveness } \\
\cline { 2 - 3 } & Model 1 & Model 2 \\
\hline Gender & 0.108 & 0.007 \\
\hline Age & -0.371 & -0.143 \\
\hline Learning stage & 0.028 & -0.014 \\
\hline Cultural identity & & $0.695^{* * *}$ \\
\hline R2 & 0.001 & 0.483 \\
\hline Delta R2 & & 0.482 \\
\hline
\end{tabular}

Note: The reported coefficients in the table are the results of the test of each model respectively 
The above table shows that the correlation coefficient between cultural identity and learning effectiveness is 0.695 $(p<0.001 ;$ Model2) . Under the condition of taking control variables into consideration, the variance interpretation rate of cultural identity on students' learning effectiveness reached $48.3 \%$, indicating that the higher the cultural identity is, the more obvious the students' learning effectiveness will be. Hypothesis H1 is supported by empirical data. It can be seen that the learning effectiveness of foreign students is closely related to their cultural identity, and the improvement of their cultural identity will be helpful to the improvement of their learning effectiveness. In the study of how to improve the learning effectiveness of foreign students, school teachers and others can consider some ways to improve the cultural identity of foreign students first, and then improve the learning effectiveness of foreign students.

TABLE IV. REGRESSION MODEL ANALYSIS OF PROACTIVE PERSONALITY AND LEARNING EFFECTIVENESS(N=112)

\begin{tabular}{|l|c|c|}
\hline \multirow{2}{*}{$\begin{array}{c}\text { Models and } \\
\text { variables }\end{array}$} & \multicolumn{2}{c|}{ Learning effectiveness } \\
\cline { 2 - 3 } & Model 1 & Model 2 \\
\hline Gender & 0.018 & -0.019 \\
\hline Age & -0.207 & -0.109 \\
\hline Learning stage & 0.028 & -0.055 \\
\hline Proactive personality & & $0.719^{* * *}$ \\
\hline R2 & 0.001 & 0.509 \\
\hline Delta R2 & & 0.508 \\
\hline
\end{tabular}

Note: The reported coefficients in the table are the results of the test of each model respectively. $\mathrm{K}$ means $\mathrm{P}<0.10$, $\mathrm{P}<0.05, * * \mathrm{P}<0.01, * * * \mathrm{P}<0.001$

The above table shows that the correlation coefficient between initiative personality and learning effectiveness is $0.719(\mathrm{p}<0.001 ;$ Model 2$)$. Under the condition of taking control variables into consideration, the variance interpretation rate of initiative personality on students' learning effectiveness reached $50.8 \%$, indicating that the higher the initiative personality is, the more obvious the students' learning effectiveness will be. Hypothesis $\mathrm{H} 2$ is supported by empirical data. This provides some enlightenment in training and selecting overseas students. Schools should pay attention to the cultivation of students' initiative personality and organize related activities to help students realize the importance of initiative personality and encourage them to work hard to cultivate and strengthen their initiative.

TABLE V. THE MODERATING EFFECT OF INITIATIVE PERSONALITY ON CULTURAL IDENTITY AND LEARNING EFFECTIVENESS (N=112)

\begin{tabular}{|l|c|c|c|}
\hline \multirow{2}{*}{\multicolumn{1}{c|}{$\begin{array}{c}\text { Models and } \\
\text { variables }\end{array}$}} & \multicolumn{3}{c|}{ Learning effectiveness } \\
\cline { 2 - 4 } & Model 1 & Model 2 & Model3 \\
\hline Gender & 0.108 & -0.012 & -0.011 \\
\hline Age & -0.371 & -0.157 & -0.127 \\
\hline Learning stage & 0.028 & -0.049 & -0.045 \\
\hline Cultural identity & & $0.400^{* *}$ & $0.385^{* *}$ \\
\hline Active personality & & $0.456^{* *}$ & $0.455^{* *}$ \\
\hline Cultural Identity $\times$ & & & 0.070 \\
Active Personality & & & 0.605 \\
\hline R2 & 0.001 & 0.600 & 0.005 \\
\hline Delta R2 & & 0.599 & \\
\hline
\end{tabular}

Note: The reported coefficients in the table are the results of the test of each model respectively. $\mathrm{K}$ means $\mathrm{P}<0.10,{ }^{*} \mathrm{P}<0.05,{ }^{*} \mathrm{P}<0.01,{ }^{*} * * \mathrm{P}<0.001$

Model $3(0.070, p>0.05 ;)$ shows that the interaction between cultural identity and initiative personality has a positive effect on learning effectiveness, but the effect is not significant. It can be concluded that active personality does not play a moderating role in the relationship between cultural identity and learning effectiveness. Suppose H3 is not true. The reasons may be as follows: Firstly, it is influenced by the way the school teaches. Everyone receives the same education and receives the same learning resources. Under the same cultural identity, whether the initiative personality is strong or not will not affect the amount of learning resources students receive, and then will not affect the learning effectiveness. Secondly, it is influenced by individuals' subjective bias. Among the students with the same sense of cultural identity, the one with strong initiative personality does not require too much for personal learning goals, and will not spend more energy on targeted learning after learning to a certain extent. Although initiative personality is strong, the learning effect will not be significantly improved.

\section{CONCLUSION AND DISCUSSION}

This study explores the influencing factors of learning outcomes of foreign students from the perspectives of cultural identity and initiative personality, and then examines the moderating effect of initiative personality between cultural identity and learning outcomes of foreign students. Generally speaking, this study draws the following conclusions: Firstly, cultural identity has a positive impact on learning effectiveness. The higher the degree of cultural identity is, the better the learning effect can be. Secondly, initiative personality has a positive impact on the learning effectiveness of foreign students. That is, the more active personality is, and the better the learning effect is.

\section{A. Theoretical and practical significance}

The theoretical significances are as follows. This study integrates cultural identity with initiative personality and learning effectiveness of foreign students in a framework model, which provides a new perspective and new ideas for the study of learning effectiveness of foreign students. This paper has verified the moderating effect of active personality through empirical research, enriching the study of learning effectiveness of overseas students in the background of the whole area.

The practical significances are as follows. First of all, we should further enhance the Chinese language ability of foreign students, including listening, speaking, reading and writing. The mastery of Chinese language ability is directly related to the understanding and acceptance of Chinese culture by foreign students. It is the basis and prerequisite for understanding Chinese culture. Secondly, we should give guidance and help to students from different cultural backgrounds, especially those from African countries. Because of the great gap between their cultural backgrounds and Chinese culture, it is difficult to introduce Chinese. Thirdly, we should explore different forms of teaching. In addition to traditional classroom teaching, we should add extra-curricular teaching links and contents. We should encourage students to go out of the campus and actively integrate into Chinese life. Especially, we should increase cross-cultural communication courses combining theory with practice. 


\section{B. Deficience and prospects}

First of all, as the research object is a group of overseas students studying in China, there are many restrictions on the choice of samples. The subjects are mainly from universities in Yunnan. The coverage and quantity of samples need to be improved. Finally, in the hypothesis test, such as the third test result, active personality has no moderating effect on the relationship between cultural identity and learning effectiveness. Although there are reasons for it, whether it is the reason or not remains to be studied.

\section{ACKNOWLEDGMENT}

This paper was finished during my first year of graduate school. Although I have put all my energy into it, there are still many deficiencies in this paper. At the international conference, I really hope that I can better perfect myself and improve the study of this paper. Finally, I would like to express my sincere gratitude to my tutor, classmates, all editors and reviewers. My tutor and classmates gave me very important guidance and help in completing this essay. At the same time, I really hope that I could live up to everyone's expectations and produce more satisfying works in the future. Thank you very much!

\section{REFERENCES}

[1] Bateman T S G. The proactive component of organizational behavior: A measure and correlates[J]. Journal of Organizational Behavior, 1993

[2] Grant J. M. The Proactive Personality Scale and Objective Job Performance Among Real Estate Agents[J]. Journal of Applied Psychology, 1995, (80) :532-537.

[3] Allen DG W. Turnover intentions and voluntary turnover: The moderating roles of self-monitoring, locus of control, proactive personality, and risk aversion [J]. Journal of Applied Psychology, 2005, 90(5):980-990.

[4] Ruihua Ju, Qingqing Zhang, KeJia Qu. The relationship between College Students\&apos;initiative personality, career decision-making self-efficacy and career exploration [J]. Psychological development and education, 2015, 31 (04): 445-450.

[5] Zhang Jia. Investigation and Research on the Relationship between College Students\&apos;Attitudes towards Physical Education and Learning Effectiveness [D]. Yanbian University, 2018.

[6] QiFeng Li. Study on Students' Classroom Experience and Learning Effectiveness [D]. East China Normal University, 2015.

[7] JianChun Hao. The relationship between life stress, negative emotional adjustment, learning satisfaction and learning performance [D]. Tianjin University, 2005.

[8] Chunsun Ying. Introduction to Intercultural Communication Science [M]. Beijing: Peking University Press, 2008.
[9] Xiaotong Fei. Reflection, Dialogue and Cultural Consciousness [M]. Journal of Peking University: Philosophy and Social Sciences Edition, 1997.

[10] Yong Lin, Wan Minggang. Study on the Factors Affecting Tibetan and Han Cultural Identity of Tibetan College Students [J]. Psychological and Behavioral Studies, 2003, 3:181-185.

[11] Han Xianzhou, Shen Li. Exploration and Analysis of Chinese Cultural Identity Education for Overseas Students in China [J]. Heilongjiang Higher Education Research, 2018, 36 (12): 136-138.

[12] Gan Yiqun. The influence of initiative personality on career decisionmaking self-efficacy of university graduates [J].Journal of Peking University (Natural Science Edition), 2009, 45 (03): 548-554.

[13] Grant J. M. Proactive Behavior in Organizations [J]. Journal of Management, 2000:23-26.

[14] Parker S K S C. Minimizing strain and maximizing learning: The role of job demands, job control, and proactive personality [J]. Journal of Applied Psychology, 1999, 84:925-939.

[15] Seibert S E G J. Proactive personality and career success. [J]. Journal of Applied Psychology, 1999,84:416-427.

[16] Thompson J. A. Proactive Personality and Job Performance : A Social Capital Perspective [J]. Journal of Applied Psychology, 2005,90 (5) :1011-1017.

[17] Li Qing. Narrative Text Study on the Causes of the Change of Individual Motivation of Foreign Language Learners [J]. Foreign Language Teaching Theory and Practice, 2009 (02): 24-31.

[18] Wen Yao, Yiqun Gan. Active Personality and Job Performance: The Regulatory Role of Individual-Organizational Matching [J]. Applied Psychology, 2008, 14 (02): 118-128.

[19] XiaoBing Zhao. A study on the impact of prospective personality on employee performance [D]. Nanjing University of Technology, 2010

[20] Gong Y, Cheung S. M. Unfolding the Proactive Process for Creativity Integration of the Employee Proactivity, Information Exchange, and Psychological Safety Check [J]. Journal of Management, 2012, 38( 5):1611-1633

[21] Wen Fang, Jinping Mao. Review of Active Personality Theory [J]. Social Psychological Science, 2011, 26 (02): 15-19.

[22] Yang Bin. A review of the research on initiative personality [J]. Managers, 2013, 5:156-158

[23] Qiu Hongchang, Lin Nengbai. A Study of Service Quality - The Impact Analysis and Application of Personality Traits of Service Personnel [J]. Journal of Management, 1999, 16 (2): 175-192.

[24] Xie Jun, Yan Ming. Positive coping or avoidance? The mechanism of the influence of initiative personality on workplace exclusion and organizational citizenship behavior [J]. Psychological Journal, 2016, 48 (10): 1314-1325.

[25] Tinto V. Dropout from Higher Education: A Theoretical Synthesis of Recent Research[J]. Review of Educational Research, 1975,45(1):89125.

[26] Zhao Jie, Investigation and Research on Korean Students\&apos;Identity of Modern Chinese Culture [D]. Dalian University of Foreign Studies, 2019.

[27] Bateman T S G. The proactive component of organizational behavior: A measure and correlates[J]. Journal of Organizational Behavior, 1993. 